\title{
Optimization of TIG Welding Parameters for the 202 Stainless Steel Using NSGA-II
}

\author{
Neeraj Sharma*, Wathiq Sleam Abduallah**, Manish Garg***, Rahul Dev Gupta*,****, Rajesh \\ Khanna***** and Rakesh Chandmal Sharma* \\ *Department of Mechanical Engineering, Maharishi Markandeshwar (Deemed to be University), Mullana, Ambala, 133207, India \\ **Southern Technical University, Basrah, Iraq \\ ***Senior Engineer, PED Division, ISGEC Heavy Engineering Ltd., Yamunanagar, Haryana \\ *****Department of Mechanical Engineering, DAV University, Jalandhar-144012, Punjab \\ ****Corresponding Author: rdg_76@Yahoo.com
}

Submitted: 18/06/2018

Revised: $\quad 18 / 12 / 2019$

Accepted: 25/12/2019

\begin{abstract}
Tungsten Inert Gas welding is a fusion welding process having very wide industrial applicability. In the present study, an attempt has been made to optimize the input process variables (electrode diameter, shielding gas, gas flow rate, welding current, and groove angle) that affect the output responses, i.e., hardness and tensile strength at weld center of the weld metal SS202. The hardness is measured using Vicker hardness method; however, tensile strength is evaluated by performing tensile test on welded specimens. Taguchi based design of experiments was used for experimental planning, and the results were studied using analysis of variance. The results show that, for tensile strength of the welded specimens, welding current and electrode diameter are the two most significant factors with $\mathrm{P}$ values of 0.002 and 0.030 for mean analysis, whereas higher tensile strength was observed when the electrode diameter used was $1.5 \mathrm{~mm}$, shielding gas used was helium, gas flow rate was $15 \mathrm{~L} / \mathrm{min}$, welding current was $240 \mathrm{~A}$, and a groove angle of $60^{\circ}$ was used. Welding current was found to be the most significant factor with a $\mathrm{P}$ value of 0.009 leading to a change in hardness at weld region. The hardness at weld region tends to decrease significantly with the increase in welding current from 160-240A. The different shielding gases and groove angle do not show any significant effect on tensile strength and hardness at weld center. These response variables were evaluated at $95 \%$ confidence interval, and the confirmation test was performed on suggested optimal process variable. The obtained results were compared with estimated mean value, which were lying within $\pm 5 \%$.
\end{abstract}

Keywords: ANOVA; DOE; NSGA-II; Orthogonal array; SS202; Taguchi; Tungsten inert gas welding.

\author{
Abbreviation: \\ ANOVA: Analysis of variance \\ DOE: Design of Experiments \\ SS202: Stainless steel 202 \\ NSGA-II: Nondominated sorting genetic algorithm-II \\ P-value: Probability value \\ TIG: Tungsten inert gas
}

TS: Tensile strength 


\section{INTRODUCTION}

Tungsten Inert Gas (TIG) welding is commonly used for the joining of different metals such as mild steel, aluminum, and stainless-steel alloy grades. A nonconsumable tungsten electrode is used in TIG welding for the generation of heat and melting of work-piece surface. An inert gas is used for preventing the exposure of arc zone to the atmosphere. The joining of stainless steel is challenging by fusion weld due to retainment of heat. Consequently, the weld defect such as rust, embrittlement, and warping can occur. The TIG welding is preferred for the joining of stainless steel as the joints are non-hardenable upon cooling and reveal good toughness characteristics, due to which there is no need of pre-weld or post-weld treatment. The structure of weld can be predicted by its chemical composition. The chromium (plus niobium, molybdenum, and silicon) promotes the formation of ferrite; however, nickel (plus nitrogen, manganese, and carbon) leads the formation of austenitic steel. The TIG welding process can be utilized in a variety of applications including rail vehicle body shell design, transistor cases, instrument diaphragms, and precision welding in atomic energy, aircraft, instrument industries, and rocket motor chamber fabrications in launch vehicles. Also, the applications of TIG welding were found in material fabrication, chemical, automobile, aviation, and space-craft industries (Juang and Tarng, 2002).

Typical TIG input process variables are weld voltage, weld current, welding speed, type of shielding gas, gas flow rate, root gap, and groove angle. Parametric optimization of TIG welding plays a noteworthy role in the quality of product like mechanical properties, joint efficiency, weld distortion, etc. (Tseng and Hsu, 2011). Tarng and Yang (1998) used Taguchi application to analyze the significance of input variables on weld bead. Taguchi method was used for experimental planning, and optimal parametric conditions were obtained. The gas tungsten arc welding is used for the joining of AA1100. Gao et al. (2007) studied the outcome of shielding gas on stability of weld during $\mathrm{CO}_{2}$ laserTIG welding. The work-material used in their research work is SS316L. The plasma shape varying was used to find out the weld penetration. Manti et al. (2008) observed that process variables, especially pulse variables, affect the tensile strength (TS) and hardness of the weld and were sensitive to microstructure of the weld. High frequency produces low strength weld as compared to the low frequency under the same welding conditions. Hsieh et al. (2008) processed the dissimilar materials joining by gas tungsten arc welding (GTAW). The researchers have studied the mechanical characteristics and microstructure of dissimilar joints. During the joining, an austenitic phase and huge amount of precipitates have been observed. Feng et al. (2015) investigated the mechanical characteristics and corrosion behavior of AISI 316L stainless steel welded by TIG welding. The authors of this research investigated that single pass TIG welding without filler wire can successfully weld stainless sheet up to $10 \mathrm{~mm}$ thickness. Also, the strength of welded joint was equivalent to the base material. Bharwal and Vyas (2014) studied the weldability issue of SS202 with gas tungsten arc welding and compared it with the welded joint of SS304. It was found that, due to economics associated with the SS202, it was preferred for the number of applications. The tensile strength of welded joint was found to be suitable for indoor applications. Yadav and Kajal (2018) welded the dissimilar stainless steel (SS202 and SS316) alloys. The experiments were planned according to L9 OA, and the output parameters considered were toughness and hardness. Esme et al. (2009) worked on the parametric investigation on TIG welding to find out the favorable bead geometry. They used grey-Taguchi method application to optimize multiresponse penetration, bead height and width, area of penetration, HAZ, and tensile load simultaneously. Kumar et al. (2011) envisaged mechanical characteristics of SS AISI $304 \& 316$ using TIG \& MIG welding process. The different characteristics like hardness, strength, grain structure, ductility, and HAZ were examined in both TIG and MIG welding keeping voltage as a constant factor. Yazdani et al. (2017) studied the spring-back of two-layer sheet formed by SS304 and commercially pure copper. It was found from the research that, with the increase in the strength and Young's modulus of the material, the springback decreases. Pandey et al. (2018) investigated the TS and hardness for the dissimilar steel (P91 and P92) weld joints. The input parameters considered during the joining process were travel speed, voltage, current, heat input, and arc efficiency. The hardness of $\delta$-ferrite region was less than the hardness of martensite region.

However, very few studies reported in the literature comprehensively cover the entire welding parameters, i.e., groove angle, protecting gases, gas flow rate, welding current, groove angle, and electrode diameter for stainless steel. This will provide a full scope for the evaluation of different control variables optimization for appropriate applications. 
The present research focused on experimental determination of the effects of welding parameters like electrode diameter, protecting gases, welding current, groove angle, and gas flow rate on hardness and TS at weld center of metal SS 202. Results were analyzed using ANOVA. Further, an empirical relationship between the output responses and process parameters was developed by regression analysis. These empirical models were further processed by nondominated sorting genetic algorithm-II (NSGA-II).

\section{MATERIAL, EXPERIMENTAL SET-UP, AND PROCEDURE}

The experiments were performed on TIG welding machine (Power Tech make, TIG 400 IJ) available at welding workshop, Maharishi Markandeshwar (Deemed to be University), Mullana, India. Figure 1 demonstrates schematic of tungsten inert gas welding with its different parts. In this present experimental study, the following materials were used in TIG welding: (1) Base metal, (2) Filler metal, and (3) Shielding gas. SS 202 steel was used as a work material. The dimension of the work piece sample taken is $250 \times 150 \times 6 \mathrm{~mm}$. Table 1 gives the composition of base metal, which was found by using atomic absorption spectrometer. SS 308 steel is utilized as filler metal, and its chemical composition is C: 0.08\%; Mn: 2\%; P: 0.045\%; S: 0.03\%; S: 0.03\%; Si: 1\%; Ni: 9.8\%; Cr: 19.2\%; Fe: balance. Three different shielding gases, namely, Argon (Ar), Helium (He), and mixture of Argon and Helium (equal wt. \%age), are selected for the experiments.

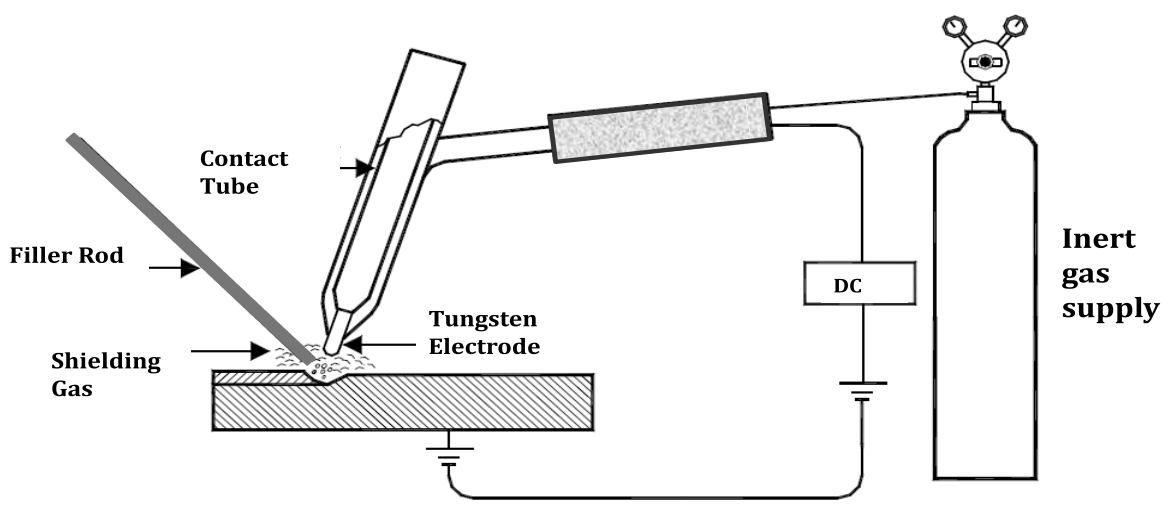

Figure 1. Schematic of TIG Welding.

Table 1. Chemical composition of SS 202 steel.

\begin{tabular}{|c|c|c|c|c|c|c|c|c|}
\hline $\begin{array}{c}\mathbf{C} \\
\mathbf{\%}\end{array}$ & $\begin{array}{c}\mathbf{M n} \\
\mathbf{\%}\end{array}$ & $\begin{array}{c}\mathbf{P} \\
\mathbf{\%}\end{array}$ & $\begin{array}{c}\mathbf{S} \\
\mathbf{\%}\end{array}$ & $\begin{array}{c}\mathbf{S i} \\
\mathbf{\%}\end{array}$ & $\begin{array}{c}\mathbf{C u} \\
\mathbf{\%}\end{array}$ & $\begin{array}{c}\mathbf{N i} \\
\mathbf{\%}\end{array}$ & $\begin{array}{c}\mathbf{C r} \\
\mathbf{\%}\end{array}$ & $\begin{array}{c}\mathbf{V} \\
\mathbf{\%}\end{array}$ \\
\hline 0.0832 & 7.426 & 0.02356 & 0.01420 & 0.3503 & 0.1050 & 4.648 & 16.94 & 0.0461 \\
\hline
\end{tabular}

Table 2. Process parameters and their levels that affect welding.

\begin{tabular}{|c|c|c|c|c|c|c|}
\hline Serial No. & Contributing Factors & Units & Level 1 & Level 2 & Level 3 & DOF \\
\hline $\mathbf{1}$ & Electrode diameter & $\mathrm{mm}$ & 1.5 & 2.4 & - & 1 \\
\hline $\mathbf{2}$ & Shielding gas & & Argon & Helium & Argon+Helium & 2 \\
\hline $\mathbf{3}$ & Gas flow rate & $1 / \mathrm{min}$ & 9 & 12 & 15 & 2 \\
\hline $\mathbf{4}$ & Welding current & $\mathrm{A}$ & 160 & 200 & 240 & 2 \\
\hline $\mathbf{5}$ & Groove angle & $\circ$ & 60 & 75 & 90 & 2 \\
\hline
\end{tabular}


Table 3. Orthogonal array for experimentation in Encoded form and Results for TS

\begin{tabular}{|c|c|c|c|c|c|c|c|c|c|}
\hline \multirow{2}{*}{$\begin{array}{l}\text { Exp. } \\
\text { No. }\end{array}$} & \multirow{2}{*}{$\begin{array}{c}\text { Electrode } \\
\text { Diameter } \\
(\mathrm{mm})\end{array}$} & \multirow{2}{*}{$\begin{array}{l}\text { Shielding } \\
\text { Gas }\end{array}$} & \multirow{2}{*}{$\begin{array}{c}\text { Gas } \\
\text { Flow } \\
\text { Rate } \\
\text { (L/min) }\end{array}$} & \multirow{2}{*}{$\begin{array}{c}\text { Current } \\
\text { (A) }\end{array}$} & \multirow{2}{*}{$\begin{array}{c}\text { Groove } \\
\text { Angle } \\
\left(^{\circ}\right)\end{array}$} & \multicolumn{2}{|c|}{$\mathrm{TS}\left(\mathrm{N} / \mathbf{m m}^{2}\right)$} & \multicolumn{2}{|c|}{$\begin{array}{l}\text { Hardness at Weld } \\
\text { Center }\end{array}$} \\
\hline & & & & & & Mean & $\mathrm{S} / \mathrm{N}$ ratio & $\begin{array}{c}\text { Mean } \\
(\mathrm{HV})\end{array}$ & $\begin{array}{c}\mathrm{S} / \mathrm{N} \\
\text { ratio }\end{array}$ \\
\hline 1 & 1.5 & $\mathrm{Ar}$ & 9 & 160 & 90 & 360 & 51.1179 & 308 & 49.7834 \\
\hline 2 & 1.5 & $\mathrm{Ar}$ & 12 & 200 & 60 & 446 & 52.9861 & 276 & 48.8154 \\
\hline 3 & 1.5 & $\mathrm{Ar}$ & 15 & 240 & 75 & 498 & 53.9433 & 222 & 46.9450 \\
\hline 4 & 1.5 & $\mathrm{He}$ & 9 & 160 & 60 & 431 & 52.6758 & 323 & 50.1836 \\
\hline 5 & 1.5 & $\mathrm{He}$ & 12 & 200 & 75 & 526 & 54.4193 & 283 & 49.0343 \\
\hline 6 & 1.5 & $\mathrm{He}$ & 15 & 240 & 90 & 562 & 54.9932 & 230 & 47.2336 \\
\hline 7 & 1.5 & $\mathrm{Ar}+\mathrm{He}$ & 9 & 200 & 90 & 475 & 53.5310 & 237 & 47.4929 \\
\hline 8 & 1.5 & $\mathrm{Ar}+\mathrm{He}$ & 12 & 240 & 60 & 544 & 54.7109 & 221 & 46.8876 \\
\hline 9 & 1.5 & $\mathrm{Ar}+\mathrm{He}$ & 15 & 160 & 75 & 439 & 52.8490 & 236 & 47.4580 \\
\hline 10 & 2.4 & $\mathrm{Ar}$ & 9 & 240 & 75 & 489 & 53.7807 & 253 & 48.0616 \\
\hline 11 & 2.4 & $\mathrm{Ar}$ & 12 & 160 & 90 & 398 & 51.9969 & 262 & 48.3653 \\
\hline 12 & 2.4 & $\mathrm{Ar}$ & 15 & 200 & 60 & 481 & 53.6415 & 217 & 46.7267 \\
\hline 13 & 2.4 & $\mathrm{He}$ & 9 & 200 & 75 & 414 & 52.3338 & 235 & 47.4211 \\
\hline 14 & 2.4 & $\mathrm{He}$ & 12 & 240 & 90 & 478 & 53.5883 & 221 & 46.8876 \\
\hline 15 & 2.4 & $\mathrm{He}$ & 15 & 160 & 60 & 380 & 51.5913 & 278 & 48.8944 \\
\hline 16 & 2.4 & $\mathrm{Ar}+\mathrm{He}$ & 9 & 240 & 60 & 459 & 53.2332 & 237 & 47.4929 \\
\hline 17 & 2.4 & $\mathrm{Ar}+\mathrm{He}$ & 12 & 160 & 75 & 372 & 51.4100 & 268 & 48.5620 \\
\hline 18 & 2.4 & $\mathrm{Ar}+\mathrm{He}$ & 15 & 200 & 90 & 415 & 52.3598 & 227 & 47.1195 \\
\hline
\end{tabular}

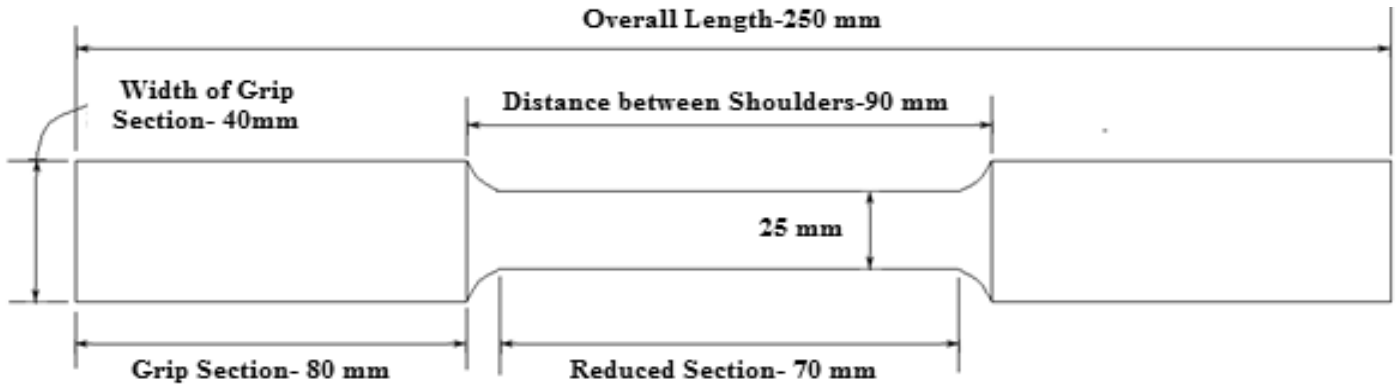

Figure 2. Schematic diagram for tensile test specimen. 


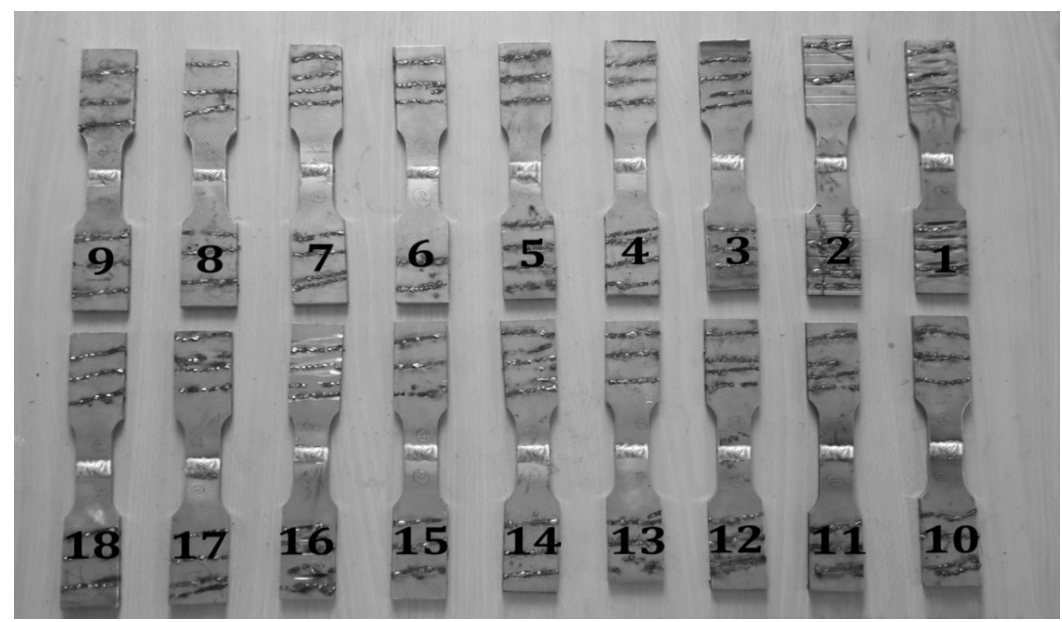

Figure 3. Specimen for tensile testing.

The determination of contributing factors, which need to be explored, depends on the responses of interest. Preliminary study was carried out for the identification of control variables, which affects the responses as shown in Table 2. Five significant control variables considered in the present work are electrode diameter, shielding gas, gas flow rate, welding current, and groove angle, in which one factor varied at 2 levels and four factors varied at 3 levels. Out of this, the groove angle may be defined as the total included angle of the groove between the specimens to be joined by the groove weld. The variation in the angle varies with the properties of weld joints. Taguchi $\mathrm{L}_{18}$ orthogonal array (OA) with five columns and eighteen rows was used for experimentation. The welding parameters using the $\mathrm{L}_{18}$ OA in encoded form are shown in Table 3.

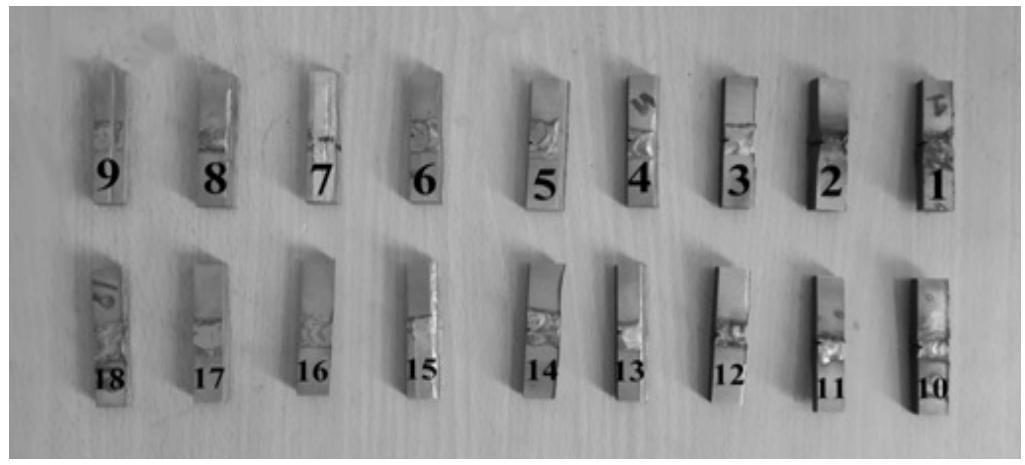

Figure 4. Hardness test specimen.

Tensile specimens were developed as per the ASTM standards for experimentation. Figure 2 provides the schematic of tensile test specimen. Figure 3 depicts the specimens for tensile test, after machining on wire cut EDM machine. The specimens were developed in such a way that the weld-joint comes in between the gauge length of tensile specimen. Figure 4 represents the specimens used for hardness test at weld center. The hardness is measured at three points on the welded joint, and the average of three is used for analysis purposes to maintain the statistical accuracy. The tensile testing was carried on Computerized Universal Testing Machine (Hitech make), and hardness of the weld region was computed by using Mitutoyo make hardness tester (computer integrated). The measurement depended on the size of indentation on the samples. The diagonals of the indents gave a direct hardness Vickers number (HV) for hardness. The hardness values obtained were useful indicators of material properties. The $10 \mathrm{kgf}$ load was applied on the indenter for $15 \mathrm{~s}$ dwell time. All experiments were carried out at the testing lab of Chandigarh Industrial and Tourism Development Corporation limited, Chandigarh. 


\section{Optimization model}

Taguchi experimental design (Roy, 2001; Jangra et al., 2016) is a powerful tool for the investigation of the influence of control factors and their interactions on the response variables. The TS and hardness at weld center tests on the TIG welding specimens were carried out under different operating conditions by considering five parameters, namely, shielding gas, electrode diameter, welding current, gas flow rate, and groove angle, as given in Table 2 as per $\mathrm{L}_{18} \mathrm{OA}$ (Montgomery, 2000; Khanna et al., 2015). The degree of freedom for each process variable is given in Table 4. It is evident from the table that the sum of the degrees of freedom of all process variables is nine. Therefore, any OA having degree of freedom greater than nine is suitable for the analysis and also depicting mix-level design. Thus, $\mathrm{L}_{18}$ presents degree of freedom equal to 17 and is having mixed-level design selected in the present research. The impact of all the contributing factors is studied using $\mathrm{L}_{18}$ array, and the tests are performed as per the DOE.

An OA gives minimum experimental sets plan, signal to noise $(\mathrm{S} / \mathrm{N})$ ratio, which helps in optimizing the response variable. The ratio of the significant factors to the nonsignificant factors is termed as $\mathrm{S} / \mathrm{N}$ ratio. Also, it is the ratio of signal (controllable factor) to noise (uncontrollable factors). This $\mathrm{S} / \mathrm{N}$ ratio is affected by process, which is to be optimized. S/N ratio for maximum TS and hardness at weld center can be expressed as "larger is better" characteristics and computed by Equation (1):

$\left(\frac{\mathrm{S}}{\mathrm{N}}\right)_{\mathrm{HB}}=-10 \log \left(\mathrm{MSD}_{\mathrm{HB}}\right)$

where $\mathrm{MSD}_{\mathrm{HB}}=\frac{1}{\mathrm{R}} \sum_{\mathrm{j}=1}^{\mathrm{R}}\left(\frac{1}{\mathrm{y}_{\mathrm{j}}}\right)^{2}$

Here, $\mathrm{R}$ - number of repetitions,

$\mathrm{MSD}_{\mathrm{HB}}-$ mean square deviation for higher the better type response

and $y_{j}-$ observed value of the output variable

After calculating this value, the confidence interval for confirmation experiments, population, optimal design, and regression equation for the responses were also calculated. The regression analysis is the procedure by which the empirical model is to be developed.

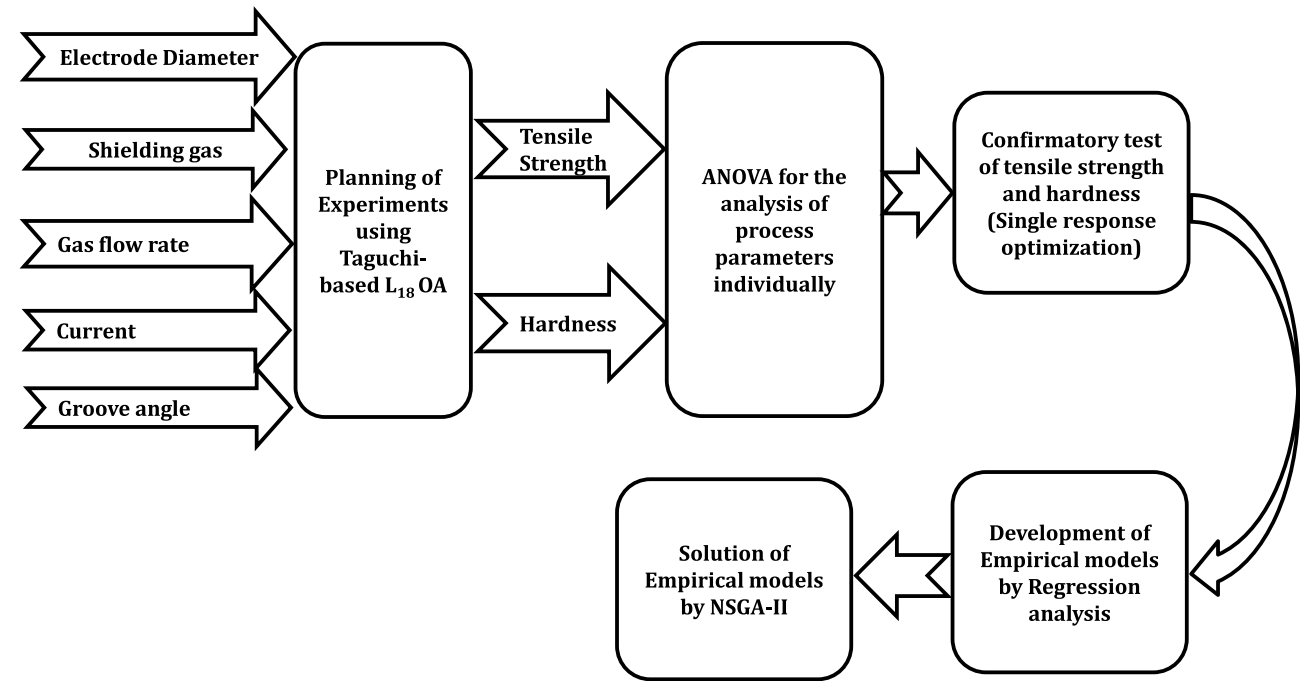

Figure 5. Process flow in present work. 
These empirical models represent the variation of one response with respect to the input process variables (Bouacha et al., 2010). The analysis of variance provides the identification of the process parameters regarding its significance. It gives the percentage contribution of each individual in the evaluation of the response characterisitcs. Further, the empirical models developed by regression analysis were solved by NSGA-II. In this, the nondominated sorting solutions are identified according to the search space and the available population (Deb et al., 2002). Figure 5 represents the flow process adopted in the present work.

\section{RESULTS AND DISCUSSION ANOVA for TS and Hardness}

Table 3 gives the values of mean TS for the eighteen trials. The three readings of TS corresponding to each parameter setting are provided in Table A1 (Appendix). The experiments were conducted according to the parameters setting shown, and the results were analyzed by ANOVA (Table 4). Table 4 shows that P-value for electrode diameter and welding current are 0.030 and 0.002 , i.e., less than 0.05 , indicating that welding current and electrode diameter are the major significant factors for the TS. Table A2 depicts the response table for the mean values of TS. It also gives the information regarding the order of influence of input parameters on TS. Figure 6 shows the main effect plots and gives variation in TS with the change in the input factors, i.e., electrode diameter, shielding gas, gas flow rate, welding current, and groove angle. It could be seen from Figure 6 that welding current and electrode diameter cause the most significant change in the TS. Shielding gas, gas flow rate, and groove angle have very low effect on TS.

Table 4. ANOVA for mean values.

\begin{tabular}{|c|c|c|c|c|c|c|c|c|c|}
\hline \multirow{2}{*}{ Source } & \multirow{2}{*}{$\mathbf{D F}^{*}$} & \multicolumn{4}{|c|}{ TS } & \multicolumn{4}{|c|}{ Hardness } \\
\hline & & $\mathbf{S S}^{*}$ & $\mathbf{M S}^{*}$ & $\mathbf{F}^{*}$ & $\mathbf{P}^{*}$ & $\mathbf{S S}^{*}$ & $\mathbf{M S}^{*}$ & $\mathbf{F}^{*}$ & $\mathbf{P}^{*}$ \\
\hline $\begin{array}{c}\text { Electrode } \\
\text { Diameter }(\mathbf{m m})\end{array}$ & 1 & 8668.1 & 8668.1 & 6.92 & 0.030 & 1065.7 & 1065.7 & 2.63 & 0.144 \\
\hline Shielding Gas & 2 & 1264.1 & 632.1 & 0.50 & 0.622 & 1924.5 & 962.3 & 2.37 & 0.155 \\
\hline $\begin{array}{c}\text { Gas Flow Rate } \\
(1 / \mathrm{min})\end{array}$ & 2 & 2234.8 & 1117.4 & 0.89 & 0.447 & 2867.4 & 1433.7 & 3.53 & 0.080 \\
\hline Current (A) & 2 & 35508.8 & 17754.4 & 14.18 & 0.002 & 7420.2 & 3710.1 & 9.14 & 0.009 \\
\hline Groove Angle $\left(^{\circ}\right)$ & 2 & 295.4 & 147.7 & 0.12 & 0.890 & 425.4 & 212.7 & 0.52 & 0.611 \\
\hline Residual Error & 8 & 10018.4 & 1252.3 & & & 3247.5 & 405.9 & & \\
\hline Total & 17 & 57989.6 & & & & 16950.7 & & & \\
\hline
\end{tabular}

*DF: degree of freedom; SS: Sum of squares; MS: Mean square; F: Tabulated F-ratio; P: Probability value 


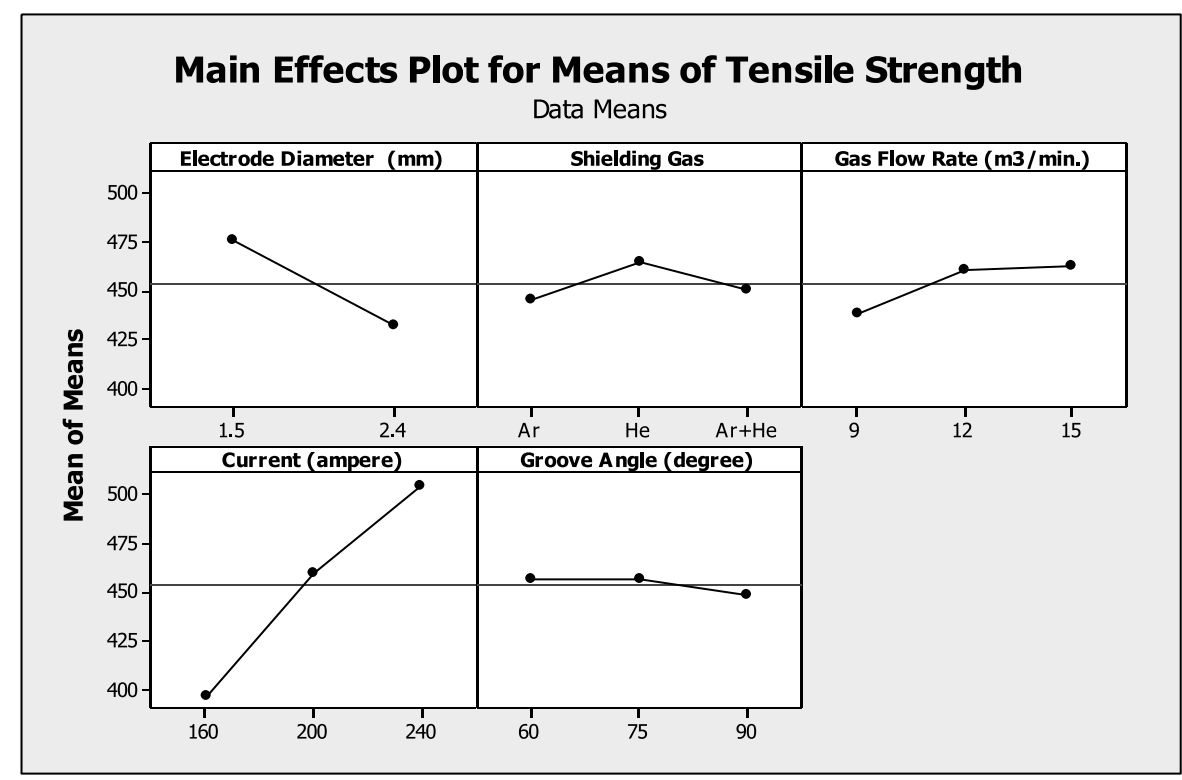

Figure 6. Main effect plot for tensile strength.

It can be seen from Figure 6 that, with the increase in welding diameter, the TS decreases. This is due to stable and precise arc in case of low diameter electrode. A high value of diameter increases the amperage in the joint, which causes the excessive heat and electrode material melt and drop off. The best value of TS is obtained in case of He environment; however, the TS value decreases if welding environment changes from He to Ar or combination of Ar \& He. The probable reason for high TS in the atmosphere of He is the higher heat input in case of He, which increases the depth to width ratio in welding and makes the weld joint stronger. TS increases with the increase in gas flow rate.

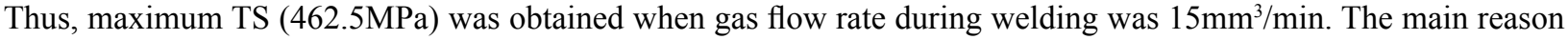
for high TS is that the air present in the atmosphere reacts with the weld pool. But the increase in the gas flow rate decreases the chances of reaction of weld pool with the air. Therefore, the increase in the gas flow rate increases the TS. With the increase in current from $160 \mathrm{~A}$ to $240 \mathrm{~A}$, the TS increases from $396.7 \mathrm{MPa}$ to $505 \mathrm{MPa}$. This is due to deep penetration of weld pool with the increase in the current value. High value of current ameliorates the heat flux intensity in the weld joint and makes a deep penetration to develop a high strength joint. The increase in groove angle is from $60^{\circ}$ to $90^{\circ}$, and TS decreases slightly from $456.8 \mathrm{MPa}$ to $448 \mathrm{MPa}$. The optimum combination of parameters for TS is given in Table 5 .

Table 5. Optimum combinations of parameters (TS).

\begin{tabular}{|c|c|c|}
\hline Electrode Diameter & Level 1 & $1.5 \mathrm{~mm}$ \\
\hline Shielding Gas & Level 2 & $\mathrm{He}$ \\
\hline Gas Flow Rate & Level 3 & $15 \mathrm{~L} / \mathrm{min}$ \\
\hline Current & Level 3 & 240 ampere \\
\hline Groove Angle & Level 1 & $60^{\circ}$ \\
\hline
\end{tabular}




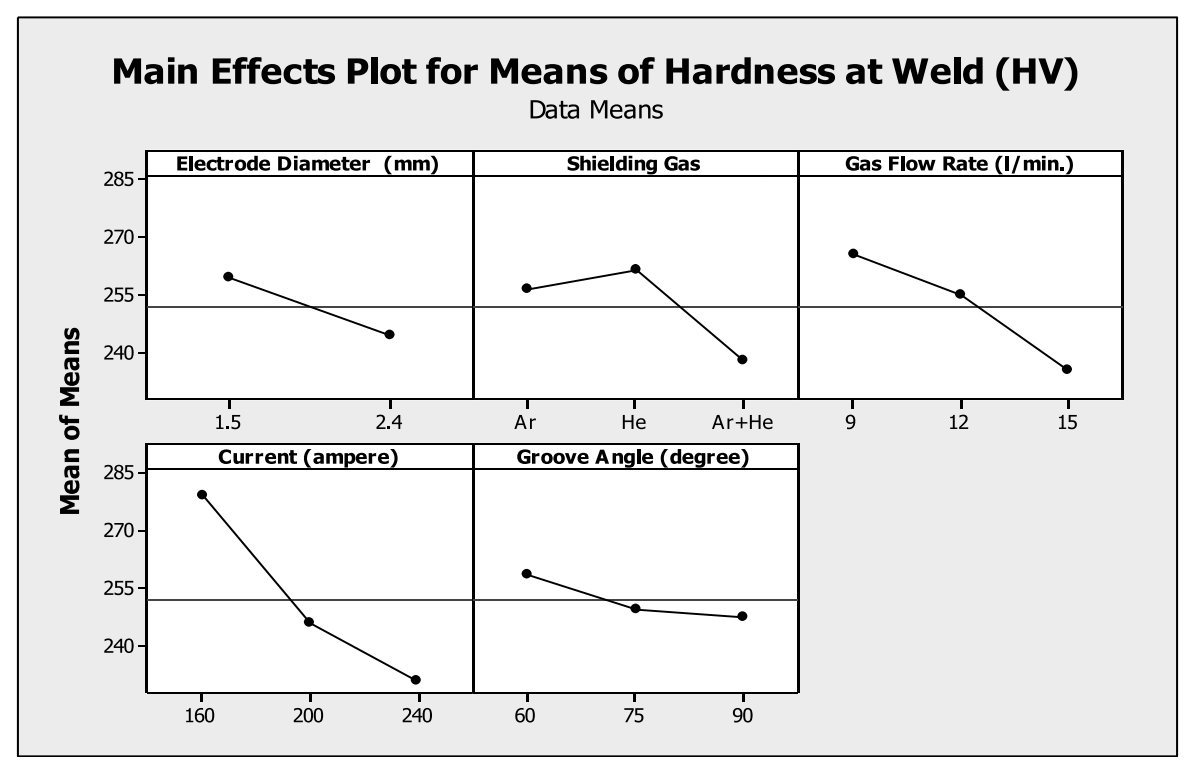

Figure 7. Main effect plot for hardness at weld center.

Figure 7 shows the variation in the hardness at weld center with the input factors, i.e., electrode diameter, shielding gas, gas flow rate, welding current, and groove angle. It could be seen from Figure 6 that small electrode diameter $(1.5 \mathrm{~mm}), \mathrm{He}$ as shielding gas, low gas flow rate $(9 \mathrm{l} / \mathrm{min})$, low value of current $(160 \mathrm{~A})$, and low groove angle $\left(60^{\circ}\right)$ suggest best hardness at welded joints. The hardness is microstructural and heat input parameters dependent. The change in process parameters makes the heat flux intensity and metallurgical behavior vary, which further affects the defects formation in the weldment. At high value of heat input, the grain growth ameliorates with a reduction in grain boundaries. This reduction increases the chances of amount of dislocation as line defects in structure.

The result of the ANOVA for mean of the hardness at weld center is also shown in Table 4. The response for mean of hardness at weld center is shown in Table A3. The response table shows the mean of each response characteristic for each level of each factor. The optimum combination of parameters for hardness is given in Table 6 .

Table 6. Optimum combination of parameters (hardness).

\begin{tabular}{|c|c|c|}
\hline Electrode Diameter & Level 1 & $1.5 \mathrm{~mm}$ \\
\hline Shielding Gas & Level 2 & $\mathrm{He}$ \\
\hline Gas Flow Rate & Level 1 & $9 \mathrm{~L} / \mathrm{min}$ \\
\hline Welding Current & Level 1 & $160 \mathrm{~A}$ \\
\hline Groove Angle & Level 1 & $60^{\circ}$ \\
\hline
\end{tabular}

\section{Empirical model for TS and Hardness}

The generation of regression equation/model is the main aim of the regression analysis (Horng et al., 2008; Bouach et al., 2010; Sahoo and Pradhan, 2013; Sharma et al., 2016). This analysis develops a relation in between the output response and input parameters. The regression equation for TS and hardness is given by Equation 2 and Equation 3. This regression equation was found using linear regression analysis.

$$
\mathrm{TS}\left(\mathrm{N} / \mathrm{mm}^{2}\right)=251-48.8 \times \varnothing+4.08 \times \mathrm{Q}+1.35 \times \mathrm{C}-0.294 \times \alpha
$$


Hardness at Weld Center $(\mathrm{HV})=496-17.1 \times \varnothing-5.07 \times \mathrm{Q}-0.607 \times \mathrm{C}-0.372 \times \alpha$

where $\varnothing$ is the Electrode Diameter in mm,

$\mathrm{Q}$ is the Gas Flow Rate in $\mathrm{L} / \mathrm{min}$,

$\mathrm{C}$ is the Welding Current in ampere,

and $\alpha$ is the groove angle in degree.

\section{Confirmatory test for TS and hardness}

Confirmatory test was performed at optimal parameter combination [Ø1(first level of electrode diameter) Q3 (third level of gas flow rate) C3 (third level of current) $\alpha 1$ (first level of groove angle)] to authenticate the validity of optimal setting. Confirmatory test's results verified the optimal parametric setting for maximum TS. The confirmation test was accomplished by selecting parametric setting as given in Table 5 (for TS) and Table 6 (for hardness). The confirmation tests expressed that the percentage error associated with weld TS of the SS202 was 2.96\%, which is under acceptable range as shown in Table 7. At the optimal parameter combination ( $1 \mathrm{Q} 1 \mathrm{C} 1 \alpha 1)$, samples for hardness test were developed, and then experiments were performed to check the validity of results. The confirmation tests expressed that the percentage error associated with hardness at weld center of the SS202 was 1.04\%, which is under acceptable range as shown in Table 7.

Table 7. Confirmation test results for TS and hardness.

\begin{tabular}{|c|c|c|c|c|c|c|}
\hline Response & $\begin{array}{r}\text { Obtained opt } \\
\text { parametric con } \\
\text { Taguchi me }\end{array}$ & $\begin{array}{l}\operatorname{lum} \\
\text { tion by } \\
\text { od }\end{array}$ & $\begin{array}{l}\text { Mean value } \\
\text { using the } \\
\text { optimal } \\
\text { condition }\end{array}$ & $\begin{array}{l}\text { Prediction } \\
\text { using } \\
\text { Regression } \\
\text { Equation }\end{array}$ & Experimental & $\begin{array}{l}\text { \%age } \\
\text { Error }\end{array}$ \\
\hline \multirow{4}{*}{ TS } & $\begin{array}{c}\text { Electrode } \\
\text { Diameter }(\emptyset)\end{array}$ & $1.5 \mathrm{~mm}$ & \multirow{4}{*}{$\begin{array}{c}526.98 \pm \\
27.50\end{array}$} & \multirow{4}{*}{545.36} & \multirow{4}{*}{562} & \multirow{4}{*}{2.96} \\
\hline & Gas Flow Rate (Q) & $15 \mathrm{~L} / \mathrm{min}$ & & & & \\
\hline & Current (C) & $240 \mathrm{~A}$ & & & & \\
\hline & Groove Angle ( $\alpha$ ) & $60^{\circ}$ & & & & \\
\hline \multirow{4}{*}{ Hardness } & $\begin{array}{c}\text { Electrode } \\
\text { Diameter }(\emptyset)\end{array}$ & $1.5 \mathrm{~mm}$ & \multirow{4}{*}{$279.3 \pm 21.93$} & \multirow{4}{*}{305.28} & \multirow{4}{*}{308.5} & \multirow{4}{*}{1.04} \\
\hline & Gas Flow Rate (Q) & $9 \mathrm{~L} / \mathrm{min}$ & & & & \\
\hline & Current (C) & $160 \mathrm{~A}$ & & & & \\
\hline & Groove Angle ( $\alpha$ ) & $60^{\circ}$ & & & & \\
\hline
\end{tabular}

\section{MULTIRESPONSE OPTIMIZATION USING NSGA-II}

NSGA-II (Deb et al., 2002) is used to solve the empirical model developed by regression analysis. In the current research, two empirical models are developed as per the number of objectives (TS and hardness). If, for a material, TS is maximum at a particular setting, then at the same setting hardness will be minimum. Both TS and hardness are maximum the better type performance characteristics. But for the same parameter setting, both responses exhibit opposite natures. Also, different process parameters have different effects on TS and hardness, such that, for one response (say TS), current has maximum effect followed by electrode diameter, gas flow rate, shielding gas, and groove angle. On the flip side, current has the maximum effect on hardness followed by gas flow rate, shielding gas, electrode diameter, and groove angle. Thus, it becomes a challenging task to find out the parameter setting at which both performance characteristics will be optimized. Equations 4 and 5 show the objectives in the present work. 
Objective $(1)=-($ TS $)$

Objective $(2)=-($ Hardness $)$

The diversity in the suggested solutions was kept by the updated version (NSGA-II) of multiple response characteristics algorithm (i.e., NSGA) (Sharma et al., 2017; Kumar et al. 2017). The Pareto-optimal solution of multiple response characteristics type problems was investigated by the updated algorithm. In this study, the selected operator throughout NSGA-II is the number of generations: 100; population size: 100; crossover is of simulated binary type having value of 0.9 ; mutation value is 0.166 with polynomial type; and selection is of crowding distance type and nondominating sorting. The procedure for the implementation of NSGA-II is given in Srinivas \& Deb, 1994; Khullar et al., 2017.

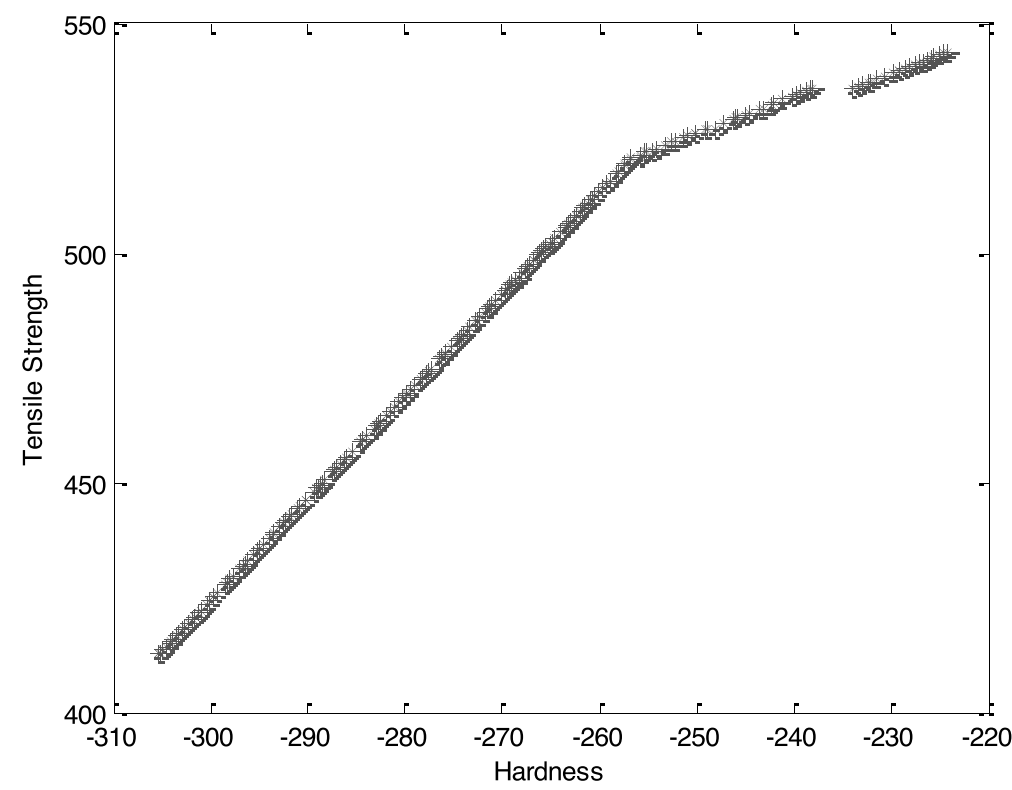

Figure 8. Pareto Optimal Solution after NSGA-II.

After regression, the mathematical model is obtained (Equations 2 and 3), and after that it is solved using evolutionary algorithm, which is characterized as multiple performance. To process and develop the algorithm, MATLAB is being used. The upper and lower bounds for input control variables are given in Equations 6 to 9.

$1.5 \leq$ Electrode Diameter $\leq 2.4$

$9 \leq$ Gas Flow rate $\leq 15$

$160 \leq$ current $\leq 240$

$60 \leq$ Groove Angle $\leq 90$

Table 8 depicts the forecast optimal solution after including the upper and lower limits during NSGA-II. These are communal Pareto optimum solutions for TS and hardness. It is observed from Figure 8 that hardness decreases as TS increases. Table 8 represents the foreseen Pareto-optimal solution (merely 20 solutions are epitomized) after 1000 generations. Out of the solutions so obtained, none can be considered better than the other. It depends on the prerequisite of product and the manufacturer. 
Table 8. Solutions suggested by NSGA-II.

\begin{tabular}{|c|c|c|c|c|c|c|}
\hline Sr. No. & $\begin{array}{c}\text { Electrode } \\
\text { Diameter }\end{array}$ & $\begin{array}{c}\text { Gas Flow } \\
\text { Rate }\end{array}$ & Current & $\begin{array}{c}\text { Groove } \\
\text { Angle }\end{array}$ & TS & Hardness \\
\hline $\mathbf{1}$ & 1.50 & 9.00 & 160.00 & 60.00 & 412.88 & 305.28 \\
\hline $\mathbf{2}$ & 1.50 & 15.00 & 240.00 & 65.36 & 543.75 & 224.30 \\
\hline $\mathbf{3}$ & 1.50 & 9.00 & 160.00 & 60.00 & 412.88 & 305.28 \\
\hline $\mathbf{4}$ & 1.50 & 13.07 & 240.00 & 65.44 & 535.86 & 234.05 \\
\hline $\mathbf{5}$ & 1.50 & 12.65 & 240.00 & 60.03 & 535.75 & 238.22 \\
\hline $\mathbf{6}$ & 1.50 & 9.00 & 169.84 & 60.00 & 426.17 & 299.30 \\
\hline $\mathbf{7}$ & 1.50 & 9.05 & 195.98 & 60.05 & 461.66 & 283.15 \\
\hline $\mathbf{8}$ & 1.50 & 9.00 & 188.05 & 60.00 & 450.74 & 288.25 \\
\hline $\mathbf{9}$ & 1.50 & 9.00 & 195.01 & 60.03 & 460.13 & 284.01 \\
\hline $\mathbf{1 0}$ & 1.50 & 9.00 & 205.94 & 60.04 & 474.88 & 277.38 \\
\hline $\mathbf{1 1}$ & 1.50 & 9.00 & 209.46 & 60.04 & 479.64 & 275.24 \\
\hline $\mathbf{1 2}$ & 1.50 & 13.59 & 240.00 & 65.32 & 538.01 & 231.45 \\
\hline $\mathbf{1 3}$ & 1.50 & 9.00 & 186.12 & 60.00 & 448.15 & 289.42 \\
\hline $\mathbf{1 4}$ & 1.50 & 9.00 & 236.26 & 60.07 & 515.75 & 258.94 \\
\hline $\mathbf{1 5}$ & 1.50 & 9.00 & 171.02 & 60.13 & 427.72 & 298.54 \\
\hline $\mathbf{1 6}$ & 1.50 & 9.68 & 240.00 & 60.00 & 523.57 & 253.25 \\
\hline $\mathbf{1 7}$ & 1.50 & 11.37 & 240.00 & 60.00 & 530.47 & 244.67 \\
\hline $\mathbf{1 8}$ & 1.50 & 13.80 & 239.76 & 65.20 & 538.57 & 230.60 \\
\hline $\mathbf{1 9}$ & 1.50 & 9.00 & 207.42 & 60.00 & 476.90 & 276.50 \\
\hline $\mathbf{2 0}$ & 1.50 & 9.51 & 239.85 & 60.02 & 522.78 & 254.19 \\
\hline
\end{tabular}

\section{CONCLUSIONS}

The present research was done to investigate the effect of input parameters on weld joint quality during TIG welding of SS202. The following conclusions have been drawn from the experimental investigation

1. Welding current and electrode diameter were found as the most significant factors with P-values of 0.002 and 0.030 , respectively. Gas flow rate, shielding gas, and groove angle did not show any significant effect on TS. The mean TS using the optimal condition would be $526.98 \pm 27.50 \mathrm{~N} / \mathrm{mm}^{2}$ with electrode diameter being $1.5 \mathrm{~mm}$, shielding gas Helium, gas flow rate $15 \mathrm{~L} / \mathrm{min}$, welding current 240 ampere, and groove angle $60^{\circ}$.

2. The welding current was found to be the most significant factor with a P-value of 0.010 . Electrode diameter, shielding gas, gas flow rate, and groove angle did not show any significant effect on hardness at weld center. The mean hardness at weld center using the optimal condition would be $279.3 \pm 21.93 \mathrm{HV}$ with electrode diameter being $1.5 \mathrm{~mm}$, shielding gas Helium, gas flow rate $9 \mathrm{~L} / \mathrm{min}$, welding current 160 ampere, and groove angle $60^{\circ}$.

3. Through confirmatory tests, it is shown that the errors associated with weld TS \& hardness at weld center for the SS202 were $2.96 \%$ and $1.04 \%$, respectively, which are under the acceptable range. The results revealed that the welding current was found to be the most significant factor that affects TS and hardness at weld center. The different shielding gases, gas flow rate, and groove angle did not show any significant effect on TS and hardness at weld center. Electrode diameter did not show any significant effect on hardness at weld center but had a major effect on TS. The levels of different factors could be chosen to increase quality of weld and productivity through TIG welding. 
4. An empirical model was also developed for TS and hardness at weld center, which can be used to predict the responses while working with similar ranges of process conditions. These empirical models are further solved by NSGA-II to find out the Pareto-optimal solutions.

\section{REFERENCES}

Bharwal, S. \& Vyas, C. 2014. Weldability Issue of AISI 202 SS (Stainless Steel) Grade with GTAW Process Compared to AISI 304 SS Grade. International Journal of Advanced Mechanical Engineering, 4(6): 695-700.

Bouacha, K., Yallese, A.M., Mabrouki, T. \& Rigal, J.F. 2010. Statistical analysis of surface roughness and cutting forces using response surface methodology in hard turning of AISI 52100 bearing steel with CBN tool. International Journal of Refractory Metal and Hard Materials, 28(3): 349-361.

Deb, K., Pratap, A., Agarwal, S. \& Meyarivan, T. 2002. A fast and elitist multi-objective genetic algorithm: NSGA-II. IEEE Trans Evolutionary Computations, 6(2): 182-197.

Esme, U., Bayramoglu, M., Kazancoglu, Y. \& Ozgun, S. 2009. Optimization of weld bead geometry in Tig welding process using grey relation analysis and Taguchi method. Materials and Technology, 43(3):143-149.

Feng, Y., Luo, Z., Liu, Z., Li, Y., Luo, Y. \& Huang, Y. 2015. Keyhole gas tungsten arc welding of AISI 316L stainless steel. Materials and Design, 85(1): 24-31.

Gao, M., Zeng, X. \& Hu, Q. 2007. Effects of gas shielding parameters on weld penetration of $\mathrm{CO}_{2}$ laser-TIG hybrid welding. Journal of Material Processing Technology, 184(1-3): 177-183.

Horng, J.T., Liu, N.M. \& Chiang, K.T. 2008. Investigating the machinability evaluation of Hadfield steel in the hard turning with $\mathrm{Al} 2 \mathrm{O} 3 / \mathrm{TiC}$ mixed ceramic tool based on the response surface methodology. Journal of Materials Processing Technology, 208(1-3): 532-541.

Hsieh, C.C., Lin, D.Y., Chen, M.C. \& Wu, W. 2008. Precipitation and strengthening behavior of massive $\delta$ - ferrite in dissimilar stainless steels during massive phase transformation. Material Science and Engineering - A 477 (1-2): 328-333.

Jangra, K.K., Sharma, N., Khanna, R. \& Matta, D. 2016. An experimental investigation and optimization of friction stir welding process for AA6082 T6 (cryogenic treated and untreated) using an integrated approach of Taguchi, grey relational analysis and entropy method. Journal of Materials: Design and Applications, 230(2): 454-469.

Juang, S.C. \& Tarng, Y.S. 2002. Process parameter selection for optimizing the weld pool geometry in the tungsten inert gas welding of stainless steel. Journal of Material Processing Technology, 122(1): 33-37.

Khanna, R., Kumar, A., Garg, M.P., Singh, A. \& Sharma, N. 2015. Multiple performance characteristics optimization for Al 7075 on electric discharge drilling by Taguchi grey relational theory. Journal of Industrial Engineering International, 11(4): 459-472.

Khullar, V., Sharma, N., Kishore, S. \& Sharma, R. 2017. RSM- and NSGA-II-Based Multiple Performance Characteristics Optimization of EDM Parameters for AISI 5160. Arabian Journal of Science and Engineering, 42(5): 1917-1928.

Kumar, S.L., Verma, S.M., Prasad, P.R., Kumar, P.K. \& Shanker, T.S. 2011. Experimental Investigation for Welding Aspects of AISI 304 \& 316 by Taguchi Technique for the Process of TIG \& MIG Welding. International Journal of Engineering Trend and Technology, 2(2): 28-33.

Kumar, V., Jangra, K.K., Kumar, V. \& Sharma, N. 2017. WEDM of nickel based aerospace alloy: optimization of process parameters and modelling. International Journal of Interactive Design and Manufacturing, 11(4): 917-929.

Manti, R., Dwivedi, D.K. \& Agarwal, A. 2008. Microstructure of Al-Mg-Si weldments produced by pulse GTA welding. International Journal of Advanced Manufacturing Technology, 36(1): 263-269.

Montgomery, D.C. 2000. Design and Analysis of Experiments. New Jersey: John Wiley \& Sons.

Pandey, C., Mahapatra, M.M., Kumar, P. \& Saini, N. 2018. Dissimilar joining of CFEF steels using autogenous tungsteninert gas welding and gas tungsten arc welding and their effect on $\delta$-ferrite evolution and mechanical properties. Journal of Manufacturing Processes, 31(1): 247-259.

Roy, R.K. 2001. Design of Experiments Using the Taguchi Approach: 16 Steps to Product and Process Improvement. New Jersey: 
John Wiley \& Sons.

Sahoo, A.K. \& Pradhan, S. 2013. Modeling and optimization of Al/SiCpMMC machining using Taguchi approach. Measurement 46(9): 3064-3072.

Sharma, N., Khanna, R., Singh, G. \& Kumar, V. 2017. Fabrication of 6061 aluminum alloy reinforced with Si3N4/n-Gr and its wear performance optimization using integrated RSM-GA, Particulate Science and Technology, 35(6): 731-741.

Sharma, N., Kumar, K., Raj, T. \& Kumar, V. 2019. Porosity exploration of SMA by Taguchi, regression analysis and genetic programming. Journal of Intelligent Manufacturing, 30(1): 139-146.

Srinivas, N. \& Deb, K. 1994. Multi objective optimization using non-dominated sorting in Genetic algorithm. Journal of Evolutionary Computations, 2(3): 241-248.

Tseng, K.H. \& Hsu, C.Y. 2011. Performance of activated TIG process in austenitic stainless steel welds. Journal of Material Processing Technology, 211(3): 503-512.

Tarng, Y.S. \& Yang, W.H. 1998. Optimization of the weld bead geometry in gas tungsten arc welding by the Taguchi method. International Journal of Advanced Manufacturing Technology, 14(8): 549-554.

Yadav, R. \& Kajal, G. 2018. Process Parameter Selection for Optimizing the Mechanical Properties of Stainless Steel (SS 202 \& SS 316) in the Gas Tungsten Arc Welding. International Journal for Research in Applied Science \& Engineering Technology, 6(4): 2684-2695.

Yazdani, A., Naseri, R. \& Rahmati, S. 2017. Investigation of springback of two-layer metallic sheet produced by explosive welding in U-die bending process. Journal of Engineering Research, 5(2): 187-206

\section{Appendix}

\section{A1: Estimated value of TS and Hardness}

At $95 \%$ confidence level, confidence interval (CI) predicts that the value of TS at optimal design conditions would be $526.98 \pm 27.50 \mathrm{~N} / \mathrm{mm}^{2}$

TS (mean value) is given by

$\mu_{\mathrm{TS}}=\mathrm{C}_{3}+\emptyset_{1}-\mathrm{T}$ (value of significant factor in response table - mean value of TS)

$=505+475.7-453.72=526.98 \mathrm{~N} / \mathrm{mm}^{2}$ [From Table A2]

$\mathrm{CI}$ around the estimated mean for TS:

C.I $=$ C.I $=\sqrt{\frac{\mathrm{F}_{\alpha}: \mathrm{v}_{1}: \mathrm{v}_{2} \times \mathrm{Ve}}{\eta_{\mathrm{eff}}}}$

$\alpha=$ Risk factor $=0.05$

$\mathrm{V}_{1}=$ D.O.F. for mean (Which is always equal 1)

$\mathrm{V}_{2}=$ D.O.F. for error $=$ Total D.O.F. - D.O. $\mathrm{F}$ of significant parameters $=17-3=14$

Now, $\mathrm{F} \alpha: \mathrm{v}_{1}: \mathrm{v}_{2}=\mathrm{F}_{0.05: 1: 14}=4.6001$ (This value finds out with the help of $\mathrm{P}$ chart with $95 \%$ confidence level)

Error variance $\left(\mathrm{V}_{\mathrm{e}}\right)=\frac{\text { SS of e pooled }}{\text { D.O.F.of e pooled }}$

SS of pooled error $=$ total SS values $-\mathrm{SS}$ value of significant factor .

$=57989.6-(35508.8+8668.1)=13812.7$

D. O. F. of e pooled $=$ Total D.O.F. - D.O. F. of significant parameters $\quad=17-3=14$ 
$\mathrm{V}_{\mathrm{e}}=\frac{13812.7}{14}=986.621$

$\eta_{\text {eff }}=\frac{18}{1+\text { D.O.F. of } \mathrm{C}_{3} \times \emptyset_{1}}=\frac{18}{1+(2 \times 1)}=6$

So C.I $=\sqrt{\frac{\mathrm{F}_{\alpha}: \mathrm{V}_{1}: \mathrm{V}_{2} \times \mathrm{Ve}}{\eta_{\text {eff }}}}=\sqrt{\frac{4.6001 \times 986.621}{6}}=27.50$

So, the CI around TS is given by $526.98 \pm 27.50 \mathrm{~N} / \mathrm{mm}^{2}$.

Mean value of hardness at weld center is given by

$\mu_{\mathrm{C} 1}=\mathrm{C}_{1}=279.3 \mathrm{HV}$

[From Table A3]

$\mathrm{CI}$ around the estimated mean for hardness at HAZ:

C.I $=\sqrt{\frac{F_{\alpha}: v_{1}: v_{2} \times V e}{\eta_{\text {eff }}}}$

C.I $=\sqrt{\frac{4.5431 \times 635.36}{6}}=21.93$

Thus, the CI around the estimated hardness at weld center is $279.3 \pm 21.93 \mathrm{HV}$.

Table A1. Readings of TS and Hardness.

\begin{tabular}{|c|c|c|c|c|c|c|}
\hline \multirow{2}{*}{$\begin{array}{c}\text { Exp. } \\
\text { No. }\end{array}$} & \multicolumn{3}{|c|}{$\mathrm{TS}\left(\mathrm{N} / \mathbf{m m}^{2}\right)$} & \multicolumn{3}{|c|}{ Hardness at weld center (HV) } \\
\hline & I & II & III & I & II & III \\
\hline 1 & 351 & 360 & 369 & 305 & 308 & 312 \\
\hline 2 & 446 & 449 & 443 & 272 & 276 & 280 \\
\hline 3 & 498 & 503 & 493 & 220 & 222 & 225 \\
\hline 4 & 417 & 445 & 431 & 321 & 323 & 325 \\
\hline 5 & 523 & 526 & 529 & 283 & 280 & 286 \\
\hline 6 & 568 & 556 & 562 & 230 & 228 & 232 \\
\hline 7 & 468 & 475 & 482 & 237 & 234 & 240 \\
\hline 8 & 544 & 549 & 539 & 220 & 222 & 221 \\
\hline 9 & 441 & 439 & 437 & 235 & 237 & 236 \\
\hline 10 & 489 & 479 & 499 & 251 & 255 & 253 \\
\hline 11 & 398 & 395 & 401 & 262 & 264 & 260 \\
\hline 12 & 476 & 486 & 481 & 214 & 220 & 217 \\
\hline 13 & 414 & 423 & 405 & 235 & 234 & 236 \\
\hline 14 & 480 & 478 & 476 & 221 & 220 & 222 \\
\hline 15 & 380 & 387 & 373 & 275 & 278 & 282 \\
\hline 16 & 452 & 466 & 459 & 237 & 234 & 240 \\
\hline 17 & 372 & 369 & 375 & 266 & 270 & 268 \\
\hline 18 & 415 & 419 & 411 & 225 & 227 & 229 \\
\hline
\end{tabular}


Table A2. Response table for means of TS.

\begin{tabular}{|c|c|c|c|c|c|}
\hline Level & $\begin{array}{c}\text { Electrode Diameter } \\
(\mathbf{m m})\end{array}$ & $\begin{array}{c}\text { Shielding } \\
\text { Gas }\end{array}$ & $\begin{array}{c}\text { Gas Flow Rate } \\
(\mathbf{L} / \mathbf{m i n} \mathbf{)}\end{array}$ & $\begin{array}{c}\text { Current } \\
(\mathbf{A})\end{array}$ & $\begin{array}{c}\text { Groove Angle } \\
\left({ }^{\circ}\right)\end{array}$ \\
\hline $\mathbf{1}$ & 475.7 & 445.3 & 438.0 & 396.7 & 456.8 \\
\hline $\mathbf{2}$ & 431.8 & 465.2 & 460.7 & 459.5 & 456.3 \\
\hline $\mathbf{3}$ & & 450.7 & 462.5 & 505.0 & 448.0 \\
\hline Delta & 43.9 & 19.8 & 24.5 & 108.3 & 8.8 \\
\hline Rank & 2 & 4 & 3 & 1 & 5 \\
\hline
\end{tabular}

Table A3. Response table for means of hardness at weld center.

\begin{tabular}{|c|c|c|c|c|c|}
\hline Level & $\begin{array}{c}\text { Electrode } \\
\text { Diameter } \\
(\mathbf{m m})\end{array}$ & $\begin{array}{c}\text { Shielding } \\
\text { Gas }\end{array}$ & $\begin{array}{c}\text { Gas Flow Rate } \\
\text { (L/min.) }\end{array}$ & $\begin{array}{c}\text { Current } \\
(\mathbf{A})\end{array}$ & $\begin{array}{c}\text { Groove Angle } \\
\left({ }^{\circ}\right)\end{array}$ \\
\hline $\mathbf{1}$ & 259.7 & 256.5 & 265.6 & 279.3 & 258.8 \\
\hline $\mathbf{2}$ & 244.3 & 261.8 & 255.2 & 245.8 & 249.6 \\
\hline $\mathbf{3}$ & & 237.7 & 235.2 & 230.8 & 247.6 \\
\hline Delta & 15.4 & 24.1 & 30.4 & 48.6 & 11.2 \\
\hline Rank & 4 & 3 & 2 & 1 & 5 \\
\hline
\end{tabular}

